\title{
UMA CONCEPÇÃO PSICANALÍTICA DE PERSONALIDADE: TEORIA DAS RELAÇÕES OBJETAIS DE FAIRBAIRN ${ }^{1}$
}

\author{
Luiz Augusto M. Celes \\ Karen Cristina Martins Alves \\ Ana Caroline Galli dos Santos"
}

\begin{abstract}
RESUMO. Este artigo tem como propósito maior desenvolver a idéia de que a teoria das relações de objeto, introduzida no movimento psicanalítico em oposição à teoria da sexualidade como base da constituição psíquica, significou uma radical mudança na concepção psicanalítica dos sujeitos. Tal mudança se expressa no abandono da pulsionalidade como fundamento subjetivo em direção à apreensão e compreensão dos sujeitos como personalidade, isto é, algo substantivamente estruturado. Metodologicamente, opta-se pela análise e exposição da principal obra de Willian Ronald D. Fairbairn (1889-1964), tomada como paradigmática das teorias das relações de objeto. Busca-se expor a evolução do pensamento fairbairniano, desde seus estudos sobre a esquizoidia - e a contradição que isso trouxe para a teoria da libido da época - até as modificações e superações que o autor se propõe a realizar na teoria psicanalítica em função da concepção da meta libidinal como sendo o objeto.
\end{abstract}

Palavras-chave: Fairbairn, teoria das relaç̃os de objeto, personalidade.

\section{A PSYCHOANALYTICAL CONCEPTION OF PERSONALITY: FAIRBAIRN'S OBJECT-RELATIONS THEORY}

\begin{abstract}
The main purpose of this essay is to develop the idea that the object-relations theory, introduced in the psychoanalytical movement as an opposition to the libido theory as basis to psychic constitution, produced a radical change in the psychoanalytical concept of subjects. Change is represented by the quitting of the drive as a subject foundation and by the apprehension and comprehension of subjects as personalities, or rather, substantially structured. In terms of methodology, the main work by William Ronald D. Fairbairn (1889-1964) was analyzed and taken as paradigmatic for all object-relations theories. The evolution of Fairbairn's thoughts, from his studies on schizophrenia - and the contradiction it brought to the contemporary libido theory - to the changes and overcoming the author proposed to accomplish in psychoanalytical theory, as a result of his finding that the libidinal goal is an object, are presented.
\end{abstract}

Key words: Fairbairn, object-relations theory, personality.

\section{UNA CONCEPCIÓN PSICOANALÍTICA DE LA PERSONALIDAD: LA TEORÍA DE LAS RELACIONES OBJETALES DE FAIRBAIRN}

\begin{abstract}
RESUMEN. Este artículo tiene como objetivo mayor el de desarrollar la idea de que la teoría de las relaciones de objeto, introducida en el movimiento psicoanalítico en oposición a la teoría de la sexualidad como base de la constitución psíquica, significó un cambio radical en la concepción psicoanalítica de los sujetos. Dicho cambio se expresa en el abandono de la pulsionalidad como fundamento subjetivo hacia la aprensión y comprensión de los sujetos como personalidad, es decir, como algo sustantivamente estructurado. Metodológicamente, se elije el análisis y exposición de la obra principal de Willian Ronald D. Fairbairn (1889-1964), tomada como paradigmática para las teorías de las relaciones de objeto. Se busca exponer la evolución del pensamiento fairbairniano, desde sus estudios sobre la esquizoidía - y la contradicción que dicho estudio trajo para la teoría de la libido de la época - hasta las modificaciones y superaciones que el autor se propone realizar en la teoría psicoanalítica en función de la concepción de la meta libidinal como sujeto.

Palabras-clave: Fairbairn, teoría de las relaciones de objeto, personalidad.

\footnotetext{
Apoio: CNPq.

* Psicanalista. Doutor em Psicologia. Professor Titular do Departamento de Psicologia Clínica do Instituto de Psicologia da Universidade de Brasília.

Il Psicóloga. Bolsista de Iniciação Científica, modalidade cota ao pesquisador - CNPq (programa 2004/2005)
}

\# Acadêmica do curso de Psicologia da Universidade de Brasília. Bolsista do Programa de Educação Tutorial (PET/PSI)
\end{abstract}


Mudanças e diversificação da psicanálise no decurso de sua história justificaram-se na ampliação do seu alcance terapêutico às configurações psicopatológicas originariamente dela excluídas (as psicoses e as perversões, por exemplo) e no entendimento de transformações das demandas de tratamento que a ela chegavam, apresentando novas organizações subjetivas e novos sintomas. (ver, p. ex., Green, 2001/2003). A compreensão da existência de novas demandas se fez parceira de mudanças sociais e culturais, acontecidas de maneira mais ou menos abruptas e mais ou menos perceptíveis ao momento (Celes, 2003). Foi assim que, na década de 40 do século passado, devido aos efeitos da Segunda Grande Guerra Mundial, traumatizados e órfãos tornaram-se objeto de preocupação de analistas como Fairbairn e Winnicott, sendo que tais casos, em sua maioria, eram formados pelo que se denominaria posteriormente de pacientes-limite ou borderlines, cuja configuração psíquica supõe-se na fronteira entre a neurose e a psicose.

Para apreender os fenômenos instituídos por essa nova clínica, importantes mudanças na compreensão da psicanálise foram realizadas, o que resultou, dentre outras coisas, em tornar secundário um de seus pilares segundo a tradição freudiana, isto é, a sexualidade.

As teorias das relações de objeto, em suas diversidades (Ogden, 2002/2003), surgem dessa nova clínica. Como base comum, elas têm o objetivo de apreender os mecanismos mais originais da constituição do ego, destacando a decisiva importância das primitivas relações de objeto em substituição à influência dos impulsos libidinais.

As teorias de relações de objeto têm sua origem, de forma efetiva, em Melanie Klein e Willian Ronald D. Fairbairn, autores que se detiveram na concepção do objeto na sua relação com o sujeito (ou vice-versa), mas também do objeto dito interno, isto é, o objeto representado, assimilado ou incorporado. A noção de um mundo interno de objetos associados pela identificação ao ego ou a suas partes cindidas compõe, de modo geral, o fundamento de suas teorias, apesar de as concepções desses dois autores possuírem consideráveis diferenças (Mitchell, 1981), que não serão aqui pormenorizadas.

É fato que, na história da psicanálise, as relações de objeto e a sexualidade não encontraram integração na teoria e no tratamento, sendo que a importância conferida a um desses aspectos tende a excluir o outro. Tal incompatibilidade pode ser observada nas dispersões no movimento psicanalítico contemporâneo. (p. ex., Green, 1997/2000; Grotstein \& Rinsley, 2000; Kernberg, 1976/1979; Ogden, 2002/2003; Siqueira, 1989).
Tendo em vista a história das incompatibilidades entre a sexualidade e as relações de objeto, este artigo tem por foco a concepção fairbairniana, tomada como radical e paradigmática com respeito ao abandono do papel da sexualidade na constituição psíquica. Desafia-nos a exposição e reflexão sobre o pensamento de W. R. D. Fairbairn, com sua exclusiva ênfase nas relações do ego com o objeto para a compreensão da constituição e estruturação psíquica. A base fundamentalmente esquizóide da personalidade e a reconsideração quanto à natureza da libido com a inversão de sua meta são os aspectos marcantes de sua concepção de personalidade.

\section{PANORAMA DAS PUBLICAÇÕES E INTRODUÇÃO À OBRA DE FAIRBAIRN: MUDANÇAS DA CONCEPÇÃO TRADICIONAL DA TEORIA DA LIBIDO}

Willian Ronald D. Fairbairn (1889-1964) desenvolveu sua obra do final dos anos 20 até o começo da década de 50 do século XX. Ela foi reunida em três livros: Estudos Psicanalíticos da Personalidade (1952/1980) - obra sobre a qual nos deteremos - e dois volumes intitulados From Instinct to Self (Birtles \& Scharff, 1994; Scharff \& Birtles, 1994).

Estudos Psicanalíticos da Personalidade (1952/1980) reúne artigos que se destacam tematicamente: a) casos clínicos anteriores às suas inovadoras formulações teóricas (1927 a 1936); b) uma variedade de artigos sobre temas como: significação sociológica do comunismo, significação de guerra, tratamento e reabilitação dos delinqüentes sexuais (1935 a 1946); c) Teoria das Relações Objetais da Personalidade, artigos nos quais faz revisões teóricas e propõe novos entendimentos à constituição psíquica (1940 a 1951).

$\mathrm{O}$ pensamento de Fairbairn desenvolveu-se no sentido da formulação de uma estruturação psíquica egóica cindida. Acompanharemos seu caminho tal como expresso em Teoria das Relações Objetais da Personalidade (Fairbairn, 1952/1980), privilegiando seus momentos teóricos e metapsicológicos. Ao final, exporemos nossa compreensão das teses que permeiam sua obra, desdobrando-nos, então, em considerações finais.

A base da teoria da personalidade em Fairbairn: descrição dos fatores esquizóides da personalidade na vida psíquica rudimentar da criança

Em Fatores Esquizóides da Personalidade, de 1940 (Fairbairn, 1952/1980), o autor pretende 
comprovar a tese de que as defesas dissociativas são fenômenos presentes na personalidade de um modo geral. Respaldando-se na experiência clínica e interessado na psicogênese do ego, identifica aproximações entre os processos do ego rudimentar da criança e os do esquizóide, que seriam: a) Tendência à orientação para um objeto parcial; b) Predomínio do tomar sobre o dar na atitude libidinal; c) Tendência à incorporação e à internalização do objeto; d) Sobrevalorização dos estados opostos de plenitude e vazio.

Estas aproximações já trazem de modo não totalmente explícito a preponderância do objeto na determinação das atitudes libidinais. É isso que constitui o gérmen das principais críticas de Fairbairn à teoria da libido freudiana, concebendo, assim, a mudança da meta libidinal.

\section{Questionamentos à Teoria da Libido freudiana - argumentando em favor da primazia do objeto}

Ao escrever Revisão da Psicopatologia das Psicoses e Psiconeuroses, em 1941, Fairbairn (1952/1980) expõe sua compreensão acerca das limitações intrínsecas à teoria da libido, a fím de justificar a proposição de uma teoria do desenvolvimento com base na qualidade da dependência do objeto.

O ponto de partida privilegiado por Fairbairn para sua crítica é a noção de zona erógena, como desenvolvida por Freud e modificada por Abraham, porque tal noção conduziria ao desprezo da qualidade e da função do objeto. Diante da compreensão da manifestação do ego como "uma atitude libidinal em busca do prazer", circunscrito na zona erógena, Fairbairn (1952/1980, p. 27), pergunta-se:

\section{Por que um lactante chupa o polegar? Nessa simples pergunta jaz todo o destino do conceito de zonas erógenas e a forma da teoria da libido baseada nele. A resposta de que o lactante chupa o polegar porque lhe proporciona prazer erótico é convincente, porém na realidade nos afasta do tema. Por que o polegar? E a resposta será: porque não tem um seio para chupar.}

$\mathrm{O}$ autor sugere que a criança, ao depender de uma relação que não pode estar atenta a todas as suas necessidades, estabelece técnicas que façam reparação a seu vínculo com o objeto, o que equivaleria a chupar o dedo. A ausência do seio, como uma relação de objeto insatisfatória, seria o determinante para uma atitude libidinal oral, e não o prazer suposto nessa zona corporal. Prosseguindo, Fairbairn contrapõe-se à suposta perspectiva freudiana segundo a qual o desenvolvimento libidinal se daria no sentido de uma integração das zonas erógenas em favor da supremacia da atitude genital. Em seu discordante ponto de vista, apenas uma relação de objeto satisfatória poderia levar à integração do ego e à atitude genital, pois é determinante para a justa compreensão do desenvolvimento da libido a relação de objeto e a integração do ego que ela propicia. ${ }^{2}$ A mudança assim entendida da meta libidinal, de busca do prazer para a busca do objeto, constitui-se no fundamento das transformações das proposições introduzidas por Fairbairn.

Fairbairn golpeia a teoria da libido para provar a existência do mundo externo (os objetos) e a necessária contribuição para o desenvolvimento do ego.

\section{Teoria do Desenvolvimento das Relações de Objeto com base na qualidade da dependência do objeto}

No mesmo texto de 1941 Fairbairn descreve uma teoria do desenvolvimento. É curioso como nomeia esta teoria: "Desenvolvimento das relações de objeto baseada na qualidade de dependência em relação ao objeto" (Fairbairn, 1952/1980, p. 28). A curiosidade dessa afirmação é que ela conduz ao entendimento de que o desenvolvimento do ego não se processa de modo autônomo, ao contrário, portanto, do que julga ser o desenvolvimento da libido a partir das zonas erógenas e da busca do prazer. De fato, para Fairbairn, o processo de desenvolvimento da personalidade define-se como desenvolvimento da relação de objeto.

O ego está, inicialmente, submetido à dependência radical do objeto. $\mathrm{O}$ processo de desenvolvimento consiste na diminuição da dependência e na progressiva diferenciação com respeito ao objeto. O propósito (um certo propósito egóico, como se verá à frente, com a noção de ego rudimentar) desse processo seria o de salvaguardar a perda do ego diante da circunstancial, porém inescapável inadequação das relações de objeto. São basicamente três, segundo Fairbairn, as fases do desenvolvimento da relação de objeto: $1^{\text {a }}$ ) dependência infantil - na qual existem duas subfases orais: a primeira, pré-ambivalente em relação ao objeto (sugar ou recusar o seio), a segunda,

Vale observar que, apesar de expor críticas à teoria da libido, a teoria das relações de objeto de Fairbairn não abandona o termo libido, ainda que produza dele um novo conceito como se verá à frente. A libido passará a ser entendida como a designação dinâmica da estrutura psíquica. 
ambivalente (sugar ou morder o seio) -; $2^{\mathrm{a}}$ ) etapa de transição, e $3^{\mathrm{a}}$ ) dependência madura.

As principais características da dependência infantil são as atitudes incorporativas e a identificação indiferenciada com o objeto. Essas características fazem com que a perda ou o afastamento do objeto sejam acompanhados pelo sentimento de aniquilação do ego. Esse aspecto é extremamente significativo na teoria, é o motivo que leva à esquizoidia como condição estruturante, pois todos passam, inevitavelmente, por essa extrema dependência oral do objeto.

$\mathrm{Na}$ etapa de transição, ocorre o início da diferenciação com o objeto. Para evitar que as frustrações impostas pelas relações objetais conduzam à perda do ego, a defesa é acionada. Sendo insuportável para o ego a ambivalência responsiva do objeto às suas necessidades, o ego cinde o objeto em suas partes: o aceito e o recusado. Esses objetos serão, no processo de desenvolvimento, internalizados ou externalizados. As neuroses clássicas são consideradas como conflito nessa fase.

Já a dependência madura, última fase do desenvolvimento das relações de objeto, é caracterizada pela possibilidade de relações menos dependentes do objeto. Fairbairn não pormenoriza técnicas defensivas nessa fase, apenas indica que o grau de dependência é diminuído, o que se esperaria de um adequado desenvolvimento.

O desenvolvimento das relações de objeto está, portanto, relacionado com o grau de identificação do ego com o objeto e com as técnicas para lidar com suas relações. Quanto maior o número de estratégias dissociativas para lidar com o objeto, maior seria a dependência infantil, ou a sua permanência e nãosuperação.

\section{A psicogênese do ego}

$\mathrm{O}$ primeiro momento em que Fairbairn fornece indícios de uma teoria da psicogênese do ego é em 1940, quando descreve o ego da criança como um ego bucal. Como o autor não volta a tematizar o caráter desse rudimento egóico, não fica clara sua natureza. É certo que em suas teorizações não há lugar para compreensões de egos rudimentares constituídos como efeitos das ações de instintos de vida ou de morte, que procuram o objeto para a gratificação. $\mathrm{O}$ ego bucal seria apenas a expressão do primeiro modo de vinculação de contato social.

Progredindo, Fairbairn mostra, em 1941, uma original compreensão das relações primitivas de objeto, aproximando as incorporações de verdadeiras assimilações dos objetos reais e concretos. $\mathrm{O}$ seio da mãe e o leite materno irão dar os primeiros contornos egóicos à criança. Em razão disso, as falhas invevitáveis nas relações objetais primitivas estruturam o ego, por meio de processo defensivo, como veremos à frente. Tais falhas correspondem à angústia de destruição e morte para a criança, que está dependente do encontro com o objeto.

A concepção de Fairbairn não exclui ou descarta a idéia de um ego inicialmente constituído, mesmo que radicalmente dependente do objeto. Talvez se encontre nesse aspecto de sua teoria um desses paradoxos teóricos, os quais estamos acostumados a encontrar em Winnicott, por exemplo, que teria usufruído bastante as formulações de Fairbairn, embora não o cite (Grotstein \& Rinsley, 2000). Este paradoxo pode ser entendido como a necessidade de se adotarem simultaneamente duas perspectivas aparentemente excludentes: 1) a do ego rudimentar e, nem tanto, já constituído - responsável pelas múltiplas defesas nas relações com o objeto, como divisão ambivalente, incorporação, identificação e repressão ou a rejeição do objeto, e, por outro lado, 2) a do ego dependente do objeto - constituindo-se de modo subordinado à qualidade da relação de objeto e estruturando-se em face dessa qualidade e, até mesmo, moldando suas defesas a ela.

Uma teoria do desenvolvimento supõe, de algum modo e a priori, um ego rudimentar que se defende das relações objetais, ou um ego dependente do objeto que se estrutura em face dessa dependência? Para Fairbairn, nenhum dos dois casos se aplica propriamente, mas sim, a proposição de uma relação de objeto que se desenvolve segundo a qualidade da dependência.

\section{Novas revisões fairbairnianas na Teoria da Repressão: lidando com objetos maus}

A dependência para com o objeto e a estruturação do ego segundo a qualidade das relações de objeto conduzem Fairbairn à revisão da teoria da repressão.

Comparando o seu próprio percurso ao anunciado por Freud em o Ego e o Id (1923/1976), que teria partido da preocupação com o reprimido para chegar posteriormente ao interesse pela instância repressora, Fairbairn (1952/1980, p. 148-149) acredita retornar ao princípio. Busca então uma compreensão do reprimido, mas agora segundo o princípio da importância do objeto.

Em Repressão e Retorno dos Objetos Maus (com especial referência às "Neuroses de Guerra"), de 1943, Fairbairn (1952/1980, p. 47-64) desenvolve a idéia principal acerca da natureza do reprimido. O reprimido consistiria em objetos maus com os quais o 
ego está identificado, e não em impulsos culpáveis ou lembranças intoleráveis, como Freud concebera.

\begin{abstract}
Acredito agora que a vítima de um ataque sexual resiste a reviver a lembrança traumática porque isto constitui um testemunho de uma relação com um objeto mau [...] é difícil conceber que a experiência de ser violado proporcione alguma gratificação [...]. É interessante assinalar que a criança vive a relação com um objeto mau não somente como algo intolerável, mas também como algo vergonhoso [...]. O fato de que a relação com um objeto mau seja vergonhosa só pode ser explicada satisfatoriamente presumindo-se que na infância precoce todas as relações de objeto estejam baseadas na identificação (Fairbairn, 1952/1980, p. 50-51).
\end{abstract}

Nesse ponto, Fairbairn demonstra conceber um estatuto bastante particular a respeito da maldade do objeto, pois, se a qualidade das relações objetais não responsivas caracteriza o grau de maldade do objeto e um grau de não-responsividade do objeto estará sempre presente, devido às necessidades do ego no estado de dependência -, a maldade torna-se uma característica do objeto, e não mais da relação.

As relações objetais responsivas na tenra infância, uma vez que cumpram a satisfação das necessidades do ego dependente, terão esgotado o seu valor, por assim dizer, na compreensão de Fairbairn. É assim que, inicialmente, para o autor, o objeto bom tem pouca relevância para a estruturação do ego. Ao contrário, predominam sobre o ego os efeitos das relações não responsivas com o objeto mau. Para evitar a dependência de objetos maus, a criança encontra modos defensivos de se relacionar com esses objetos, identificando-se com a maldade presente neles e assim se considerando má. O autor sugere que essa é uma estratégia para sobreviver em um mundo incondicionalmente mau (e que sempre será mau no sentido libidinal), visto que seria melhor para ela considerar que a maldade presente nas relações de objeto é condicional à sua pessoa, e não uma consequiência inevitável do objeto do qual depende. É mais esperançoso ser má em um mundo bom que ser boa em um mundo mau. Assim, como a criança identificou-se com a maldade, ela torna-se uma ameaça para si mesma. Ela procuraria, então, um modo de controlar e livrar o mundo externo de sua maldade e de seu potencial destruidor identificando-se com os objetos maus, trazendo-os para dentro de si e reprimindo-os. A repressão ocorreria, então, sobre os objetos maus identificados com o ego.
A essas técnicas protetoras, posteriormente, Fairbairn acrescenta a defesa moral superegóica, como internalização de objetos bons compensatórios. Os objetos maus estariam relegados ao inconsciente e a culpa seria uma forma de defesa contra as relações do ego com esses objetos. Desse modo, a criança vítima de abuso só experimentaria essa situação como algo vergonhoso porque a vergonha seria o resultado da identificação com o objeto mau e o testemunho de uma relação de dependência. A posterior internalização de objetos bons seria a forma compensatória, que impediria o sujeito de identificarse plenamente com o objeto mau. Os objetos bons encontram finalmente um lugar subsidiário na compreensão de Fairbairn, aspecto que retomaremos mais adiante.

\section{Estruturas endopsíquicas dinâmicas: inseparabilidade de estrutura e impulso}

Em 1944, o autor publica Estruturas Endopsíquicas Consideradas em Termos de Relações Objetais (Fairbairn, 1952/1980, p. 65-107) e propõe a substituição do que avalia como a antiquada psicologia dos impulsos por uma psicologia da estrutura dinâmica. Nesse ponto, Fairbairn fundamenta a proposição de um novo aparelho psíquico, em face das modificações concebidas acerca da dinâmica da repressão e, evidentemente, dirigidas novamente pela determinação do objeto na atitude libidinal.

Freud teria se baseado numa concepção atomista e molecular do aparelho psíquico. Fairbairn, leitor das novas descobertas da física, propõe uma teoria psicanalítica em consonância com a idéia de que existe uma inseparabilidade entre energia e partícula, como afirmara Heisenberg no começo do século passado. Assim, as estruturas e subestruturas não seriam preenchidas ou habitadas por representações ativadas por moções afetivas, mas seriam elas mesmas partes dinâmicas do ego, marcadas ou constituídas pelos objetos com os quais mantêm estreitas relações de dependência e identificação.

A palavra "dinâmica" tem fundamental importância para Fairbairn. Significa que o ego é, ele mesmo, ativo na busca dos objetos, não cabendo uma distinção entre ele e a suposta energia que o animaria, advinda de outra fonte (como do id, em Freud). Assim, o ego é determinado, já desde o início, pelo princípio da realidade, e não do prazer. A busca pelo prazer torna-se algo secundário e deteriorado, uma escapatória para o ego diante de sérias dificuldades de adaptação. 
No entanto, Fairbairn assume que Freud já introduzira a concepção de uma estrutura ao mesmo tempo repressora e reprimida, como seria o superego, a partir do que desenvolve a idéia de estruturas dinâmicas. Mas somente até aí vai sua aproximação com a metapsicologia freudiana, visto que, para ele, a repressão ocorre sobre os objetos maus internalizados, e não sobre representações de experiências regidas pelo princípio do prazer.

Na trilha da proposição de um novo psiquismo e depurando-o, ele considera que também são reprimidas as partes do ego, inseparáveis dos objetos. Isso quer dizer que não seria o caso de considerar que os objetos maus, e somente eles, seriam reprimidos, mas também, e fundamentalmente, as partes do ego a eles associadas, a eles vinculadas pela necessidade, na dependência, e pela identificação. $O$ resultado dessa revisão é a constituição de um aparelho cindido e dinâmico, onde uma parte dinâmica do ego reprime outras partes também dinâmicas e fortemente associadas aos objetos maus.

\section{O aparelhamento psíquico em Fairbairn}

Os artigos publicados em 1946 (Relações Objetais e Estrutura Dinâmica, p. 108-119) e 1949 (Etapas no Desenvolvimento de uma Teoria das Relações Objetais da Personalidade, p.120-127) retomam as críticas à teoria da libido e - particularmente curioso introduzem algumas ligeiras variações na estrutura psíquica.

Em termos de uma estrutura dinâmica, Fairbairn retoma a situação das relações objetais primitivas e da constituição do ego, descrevendo qual seria a origem do aparelhamento psíquico. Nesse momento, Fairbairn revela o fundamento a partir do qual se assenta sua ênfase no objeto. Reafirmando sua compreensão de libido, após considerada nas concepções em Abraham e Klein, escreve:

Do ponto de vista da psicologia das relações objetais, é axiomático que nenhum esquema de desenvolvimento libidinal pode ser satisfatório a menos que esteja baseado na consideração dos objetos naturais e biológicos do indivíduo em desenvolvimento, nos diversos estágios. (Fairbairn, 1952/1980, p. 113)

Será em face da naturalidade do objeto e de sua função biológica que Fairbairn precisará a constituição do ego. Nos momentos iniciais da vida psíquica, em que a dependência do objeto é radical, o objeto (vale dizer, o objeto externo) é separado em dois, segundo sua ambivalência fundamental: objeto bom e objeto mau. Eles são representativos da ambivalência vivida em relação à mãe e congregam, respectivamente, os aspectos responsivos e não responsivos do objeto às necessidades da dependência. Em seguida, o objeto mau é internalizado, na forma de incorporação oral, como uma tentativa de controlar a maldade presente nas relações objetais, que, então, passam a ser relações com o objeto mau internalizado. O objeto mau internalizado, que agora ameaça desde dentro, é novamente cindido, dando origem ao objeto excitante e ao objeto rejeitante/necessitado. A fim de reprimi-los e separá-los do ego, o ego utiliza-se da agressão em seu interior, força da repressão. $\mathrm{O}$ princípio predominante da dinâmica psíquica é, segundo Fairbairn, divisão e assimilação do objeto para dominá-lo.

A repressão atua sobre os objetos e sobre estruturas do ego vinculadas a eles. Assim, a repressão do objeto excitante é acompanhada pela dissociação e repressão de uma parte do ego libidinal; enquanto a repressão do objeto rejeitante é acompanhada pela dissociação e repressão de parte do ego, denominado, então, sabotador interno. A repressão dos objetos internalizados acaba por cindir o ego, precisamente pela dependência do objeto e por qualificar a estrutura do ego vinculada a ele.

O ego central - o ego que dá origem aos demais corresponde a uma estrutura primária que manteve e mesmo desenvolveu suas funções egóicas relativamente preservadas das relações não responsivas com os objetos. Esse ego mantém relações com os egos subsidiários, a saber, o ego libidinal e o sabotador interno, marcados pela repressão e cisão. Os egos subsidiários permanecem inconscientes e reprimidos, mas não menos dinâmicos.

O ego libidinal aproximar-se-ia do id freudiano, permanecendo um derivado do ego central. Esse ego manteria ainda cristalizados os vínculos com o objeto correspondente - o objeto excitante - sem perder sua força dinâmica, o que o torna profundamente ativo em relação de oposição ao ego central.

Por fim, quanto ao sabotador interno, Fairbairn nos dá uma definição confusa que inicialmente o diferencia do superego e, posteriormente, aproxima-o de sua função. Trata-se do ego identificado com o aspecto rejeitante ou destrutivo do objeto mau, que adquiriu autonomia de objeto por cisão.

Fairbairn explica que as relações entre os objetos e os egos subsidiários são libidinais, enquanto a relação dos egos entre si é movida pela agressão que reprime. Segundo o autor, o que é reprimido é um excesso de excitabilidade ou um excesso de agressão 
envolvido na relação da estrutura com os objetos internalizados.

As relações entre os egos e seus objetos são múltiplas e complexas. O ego libidinal possui uma relação de natureza libidinal com o objeto excitante. $\mathrm{O}$ sabotador interno possui uma relação de natureza também libidinal com o objeto rejeitante. A relação do sabotador interno e do ego central é de natureza agressiva e repressora para com o ego libidinal e seu objeto excitante. Por fim, o ego central também mantém uma relação de natureza agressiva e repressora com o sabotador interno e seu objeto rejeitante.

$\mathrm{Na}$ concepção fairbairniana, os egos cindidos e reprimidos, devido à maldade dos objetos aos quais estão vinculados, são dissociações do ego que não se desenvolveram na linha que avança no sentido da dependência madura. Permanecem caracterizados segundo a dependência infantil com relação aos objetos aos quais estão vinculados e identificados: egos imaturos, petrificados em suas funções egóicas, se não determinados pelo vínculo com os objetos, sendo esse vínculo também enrijecido como efeito da repressão.

Certa remissão aproximativa que Fairbairn (1952/1980, p. 126) faz da situação endopsíquica básica às noções de id, ego e superego supostas por Freud, possui afinal de contas uma função nem sequer heurística, pois o pensamento fairbairniano, em termos de uma estrutura dinâmica egóica, introduz uma radical diferença na psicanálise freudiana.

\section{CINCO TESES DO PENSAMENTO FAIRBAIRNIANO ACERCA DO PSIQUISMO}

Como vimos, o pensamento de Fairbairn não é dado de uma só vez, ele caminha em seus textos no sentido progressivo, acrescentando aspectos e deixando ou recuperando outros. Por vezes seu pensamento se torna fragmentário, particularmente quando se procura fazer dele uma apresentação detalhada. Propomo-nos, a seguir, sumarizar em cinco teses os argumentos de sua obra teórica, de forma a mostrar sua evolução e os fundamentos de uma nova compreensão. São estas as teses:

1. Os fatores esquizóides estão universalmente presentes na personalidade e possuem uma estreita relação com o funcionamento psíquico rudimentar da criança.

2. Diante da constatação da esquizoidia como um fenômeno universal e de sua relação com a dependência do objeto, a teoria da libido possui uma série de limitações intrínsecas. Empreende-se uma necessária revisão das neuroses e psicoses que destaque a primazia do objeto na constituição psíquica.

3. O ego, em sua psicogênese, está exposto a uma dependência radical do objeto, que implica em que a perda do objeto seja acompanhada pela perda do ego. Deriva-se disso que a dinâmica da personalidade depende da qualidade das primitivas relações de objeto, o que leva à consideração de que os conflitos orais - da dissociação - estão subjacentes a todos os estados clínicos.

4. Tendo em vista ainda o papel do objeto na constituição psíquica, Fairbairn (1952/1980, p. 126) considera que a repressão ocorre sobre os objetos maus, que foram internalizados e com os quais o ego está identificado. Isso significa que partes estruturais do ego são reprimidas, e não, como suporia a teoria da libido, pulsões ou representações das experiências de satisfação pulsional.

5. O prolongamento dessa revisão é a proposição de uma estrutura endopsíquica cindida, de caráter egóico e dinamicamente relacionada. A tese fairbairniana de uma estrutura dinâmica é fundamental, pois é sobre ela que o autor sustenta (ou conclui) sua radical diferença em comparação à tese de uma estrutura psíquica estimulada ou investida por uma energia, como seria a construção baseada na teoria da libido.

\section{CONSIDERAÇÕES FINAIS. FAIRBAIRN E AS TEORIAS DE RELAÇÕES DE OBJETO, UMA TRAGÉDIA DE FRAGMENTAÇÕES}

Fairbairn estabelece o problema da esquizoidia como uma condição anterior a da sexualidade pela qual o ego se estrutura ante a situação de dependência plena do objeto. Desse modo, as características orais, como formas condicionantes da relação de identificação, envolvem o sujeito fairbairniano em uma tragédia de fragmentações internas, porquanto nunca os objetos serão plenamente responsivos.

A inevitabilidade da estruturação esquizóide permite compreender que está ausente à elaboração fairbairniana o que, por outro lado, Green (1988) considera fundamental ser considerado nas relações primitivas com o objeto. Trata-se da possibilidade de recuperação da adaptação pela ação do meio, isto é, do objeto, que, assim, compensaria o estado de desvalimento absoluto em que se encontra a criança. 
Isso aponta a desconsideração de Fairbairn para com as possibilidades ou os efeitos estruturantes das relações com o objeto bom. Da obra desse autor fica a impressão de que o alcance do objeto bom se esgota na satisfação que possa fornecer à necessidade da dependência. A consideração pelo ambiente acolhedor e assegurador - que Green (1988) toma emprestada de Winnicott - e capaz de compensar ou mesmo garantir uma organização não-esquizóide do ego ausenta-se das considerações de Fairbairn.

Nesse sentido, podemos abraçar completamente a interpretação de Figueiredo (2003, p. 41-56) segundo a qual Fairbairn constitui uma verdadeira - e acrescentaríamos, concreta e efetiva - psicopatologia fundamental. Tal posição tem conseqüências na compreensão da tarefa psicoterapêutica, ao modo de um pessimismo bastante acentuado, senão radical. É verdade que Fairbairn tenta corrigir essa sua visão.

Ao final de seu artigo de 1951 (Sinopse do Desenvolvimento das Idéias do Autor sobre a Estrutura da Personalidade), Fairbairn (1952/1980, p. 128-142) acrescenta considerações sobre o valor do objeto bom para a constituição superegóica. Aí ele retoma uma idéia muito anterior, de 1940, que enfatiza a internalização do objeto pré-ambivalente da fase oral, para contrapô-la à concepção da primária internalização do objeto mal. A ambivalência, então, instaurar-se-ia na relação interna do ego com o objeto, atribuída, portanto, à ação do ego. Segue-se a compreensão de que esse processo de dissociação e repressão dos objetos rejeitante e excitante escindidos deixa no ego central um núcleo do objeto original. Este objeto, dessexualizado e idealizado, constitui-se, então, para Fairbairn, no ponto ao redor do qual se constrói o superego. Deste modo, Fairbairn busca introduzir em sua teoria as condições, também primitivas, para a influência terapêutica com base egóica. Na perspectiva psicoterapêutica, compreendea o analista como objeto bom, capaz de ganhar a boa vontade do superego, a partir do que poderia ter alguma influência sobre a dinâmica fundamentalmente esquizóide do ego. Tais reconsiderações, no entanto, não desfazem sua convicção mais acentuada, pois permanecem pouco desenvolvidas e marginais.

As perspectivas terapêuticas de Fairbairn, bem como suas interpretações socioculturais de certos e predominantes quadros psicopatológicos, podem ser bastante profícuas para a reflexão da clínica psicanalítica na contemporaneidade. Ele sugere avaliações e alternativas de compreensão que podem ser úteis para o psicanalista ou o psicoterapeuta ainda hoje, somando, e talvez até impulsionando, as perspectivas psicanalíticas do atendimento e tratamento dos chamados casos difíceis, borderlines e psicóticos (Figueiredo, 2003; Grotstein \& Rinsley, 2000). Não obstante tal riqueza, essas duas perspectivas de sua obra não são aqui desenvolvidas, pois tomamos por demarcação a intrigante teoria da personalidade construída a partir das relações de objetos e nelas fundamentada.

As críticas de Fairbairn à teoria da libido, que fundamentam o abandono da dinâmica pulsional, podem ainda ser compreendidas a partir da reinterpretação da libido como amor. Essa relação amorosa desenvolver-se-ia segundo o apego ao objeto, sustentando as frustrações que lhe são inerentes. Forçando-se um pouco o sentido, pode-se sugerir que a estrutura dinâmica de Fairbairn realiza - de uma forma impar, é verdade - a pulsão de vida, se a tomarmos em sua significação de pulsão de ligação, de constituição de vínculos. Mas não se pode desprezar a preferência da vinculação dessa estrutura dinâmica (o ego) com o objeto mau - o que pode levar à consideração de se tratar, mantendo-se a aproximação sugerida, de uma pulsão de vida que se vincula à morte, à morte psíquica, no sentido da fragmentação egóica (ou morte narcisista, se pensarmos a partir de outros termos que não os fairbairnianos). $\mathrm{O}$ psiquismo em Fairbairn, não obstante a ênfase nas relações de objeto, é um psiquismo que se fecha, voltado para si mesmo, para suas partes cindidas do ego e para os objetos internalizados.

Não obstante, o ego, na metapsicologia de Fairbairn, possui relações primitivas não apenas com objetos internalizados, mas também com objetos externos e concretos, o que aproxima a psicogênese do ego da preservação do organismo biológico. Por privilegiar a concretude da relação objetal, ensejando uma metapsicologia muito próxima da experiência infantil, podemos conceber Fairbairn como um teórico das relações objetais exclusivas, distinguindo-o dos demais teóricos das relações objetais que mantêm a designação de alguma importância para a pulsão (instinto) na constituição psíquica. Para o autor, a teoria da libido possui limitações intrínsecas que impedem uma compreensão genuína dos mecanismos primitivos de constituição psíquica. Haveria uma incompatibilidade fundamental entre a teoria da libido e a teoria das relações de objeto, visto que ambas dizem respeito aos fundamentos do psiquismo. A sexualidade somente seria experimentada e, portanto, teria vigência, posteriormente à garantia de relações objetais seguras, não sendo, conforme em Freud, inicialmente constitutiva do psiquismo. A sexualidade termina recolocada no lugar de uma função, orgânica e 
vital, que estará sujeita à consolidação das relações de objeto, ao invés de sujeitá-las.

A consequiência, comparativamente ao modelo freudiano, é a do abandono do fundamento neurótico da compreensão da estrutura psíquica, isto é, do inconsciente sexual e, na segunda formulação de Freud, do id - este último não somente como fonte pulsional, mas do sentido, assegurado desde a postulação do inconsciente em A Interpretação dos Sonhos (Freud, 1900/1972), da diferença radical do sujeito com ele mesmo. $\mathrm{O}$ inconsciente sexual freudiano pode ser propriamente entendido como condição antropológica fundamental; o ego cindido de Fairbairn, por seu lado, é condição circunstancial, embora se trate de circunstância inevitável.

Fairbairn não somente amplia Freud, se é que o faz. Ao inverter o caráter da meta libidinal, colocandoa em busca do objetivo e não, do prazer, ele pretende consolidar estados mais primitivos do funcionamento psíquico sob a base das relações de objeto e fundamentar a esquizoidia como estrutura básica e inescapável dos processos de subjetivação.

\section{REFERÊNCIAS}

Birtles, E. F. \& Scharff, D. E. (Eds.). (1994). From Instinct to Self: Selected Papers Of W.R.D. Fairbairn (Vol. II: Applications and Early Contributions). Northvale, NJ: Aronson.

Celes, L. A. (2003). Anotações para uma abordagem às demandas contemporâneas de psicanálise. Revista Brasileira de Psicanálise, 37, 1019- 1034.

Fairbain, W. R. D. (1980). Estudos Psicanalíticos da Personalidade (E. Nick, Trad.). Rio de Janeiro: Interamericana. (Original publicado em 1952).
Figueiredo, L. C. (2003). Psicanálise: elementos para a clínica contemporânea. São Paulo: Escuta.

Freud, S. (1972). A interpretação dos sonhos (J. Salomão, Trad.). Edição Standard das Obras Completas (Vol. 4 e 5). Rio de Janeiro: Imago. (Original publicado em 1900).

Freud, S. (1976). O Ego e o Id (J. Salomão, Trad.). Edição Standard das Obras Completas (Vol. 19, pp. 23- 83). Rio de Janeiro: Imago. (Original publicado em 1923).

Green, A. (1988). Narcisismo de vida, narcisismo de morte (C. Berline, Trad.). São Paulo: Escuta.

Green, A. (2000). As cadeias de Erro: Actualidade do sexual (A. P. Morais, Trad.). Lisboa: CLIMEPSI. (Original publicado em 1997).

Green, A. (Org.). (2003). Psicanálise contemporânea (A. Cabral, Trad.). Rio de Janeiro: Imago; São Paulo: SBPSP (Original publicado em 2001).

Grotstein, J. S. \& Rinsley, D. B. (Eds.). (2000). Fairbairn and the origins of object relations. New York: Other.

Kernberg, O. (1979). La teoría de las relaciones objétales y el psicoanálisis clínico (S. Abreu, Trad.). Buenos Aires: Paidós. (Original publicado em 1976).

Mitchell, S. A. (1981). The origin and nature of the "object" in the theories of Klein and Fairbairn. Contemporary Psychoanalysis, 17, 374-398.

Ogden, T. H. (2003). Uma nova leitura das origens da teoria das relações de objeto (M. L. Gastal, Trad.). Alter, 22(2), 175-195. (Original publicado em 2002).

Scharff, D. E. \& Birtles, E. F. (Eds.). (1994). From Instinct to Self: Selected papers of W. R. D. Fairbairn (Vol. I: Clinical and Theoretical Papers). Northvale, NJ: Aronson.

Siqueira, P. F. Q. (1989). O objeto na psicanálise. Percurso: Revista de Psicanálise, I(2), 18-24.

Recebido em 17/08/06 Aceito em 06/03/07

Endereço para correspondência: Luiz Augusto M. Celes. SQN 205, bloco “L”, Ap. 303, CEP 70843-120, Brasília-DF.

E-mail: celes@unb.br 